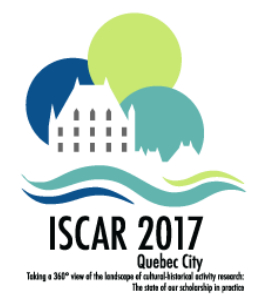

\title{
Subjectness Position Relative to Educational Activities in Different Age Periods
}

Yuriy V. Zaretskii

YZAR86@GMAIL.COM

Moscow State Psychology and Education University

Moscow, Russia

\begin{abstract}
The concept of subjectness position relative to educational activities is considered in the article as one of the central one for the reflexive-activity approach. The author's definition of this concept is given. The main results of the research concerning the attitude to educational activities in different age periods among Russian school's pupils are given, which show that, on the one hand, it is the subjectness position that is extremely important for many aspects of educational activities, but at the same time the Russian pupils subjectness position intensity decreases in the adolescent period. Nevertheless, in Russia there are pedagogical systems that contribute to the development of the pupils' subjectness position.
\end{abstract}

Keywords : Subjectness position; Educational activities; Subjectivity; Reflexive-activity approach; Junior schoolchildren; Adolescents; Senior schoolchildren; Awareness; Reflection; Educational difficulties overcoming. 


\section{Introduction}

The recent socio-economic changes taking place in our country and in the world as a whole have brought a shift in the hierarchy of values adopted in society. The attitude for consumption has led to the decrease of the education value and the academic subculture based on cognitive and educational motivation in the youth environment. The appearance of students with low motivation level and the pragmatic subculture predominance in universities is the consequence of the professional identity difficulties, the decrease in the professional development interest and at the same time following the existing family stereotypes and orientation to rapid success without special efforts (Mangels, Butterfield, Lamb, Good, \& Dweck, 2006; Rice \& Dolgin, 2012).

In middle and senior school classes, the low educational motivation often results in knowledge gaps, a distracted attitude toward the results of their activities, an external locus of control. Teachers call such adolescents difficult, uneducable, deviant.

As an answer to this challenge of time the approaches appear both in national and foreign psychology which are searching for ways to increase the motivation, the subjectum formation and the subjectness position of pupils.

Researchers and experts use different terminology: attitudes, beliefs, self-determination, subjectum, subjectness position (Deci \& Ryan, 2002; Engeström, 2006; Griffin, 1997; Mangels et al., 2006; Obukhov, 2010; Yakimanskaya, 1996; Y. V. Zaretskii, 2013; Zukerman \& Wenger, 2010). It is interesting that modern researches of the psychotherapy effectiveness (Grawe, 2006) also emphasize the psychotherapist ability to recognize the internal resources of a person to solve the problem as the main condition for successful treatment. That is, the activation of the internal human resources seems to be the key moment in the overcoming of difficulties broadly speaking (educational difficulties, psychological problems, etc.).

In our research, we rely on the concept of the subjectness position and its role in the development process worked out in the reflexive-activity approach for the psychological and pedagogical assistance providing to pupils in the educational difficulties overcoming (V. K. Zaretskii, 2013). The theoretical basis of the reflexive-activity approach was the notion about the connection between education and development in L. S. Vygotsky's cultural and historical concept (Vygotsky, 1984) concerning the cooperation of the child and the adult in the proximal development zone, the arising from the cooperative relationships thesis about the activity of the child himself relative to the activities carried out. The empirical grounds for considering the pupils' independent activity and its reflection as the key reference processes for the provision of psychological and pedagogical assistance appeared during the conduction of Summer Schools in the 1990s organized by the Institute of Pedagogical Innovations of RAE (V. K. Zaretskii, 2013; Y. V. Zaretskii, 2013). Using the example of Summer Schools, it is clearly seen that in the process of educational activities based on the reflexive-activity approach the specific learning difficulties overcoming, the educational activity successfulness increasing as a whole and the sharp increase in educational motivation take place (V. K. Zaretskii, 2001). Initially the idea that an adult and 
a child are equal subjects of cooperation was the value-based position, but children at interacting with adults, gradually began to become the subjects of their own educational difficulties overcoming. It is possible to say that the process of subject-subject relations interiorization took place (Vygotsky, 1984).

In the process of their work reflecting the consultants and teachers from the Summer School developed the principles and technologies for provision of assistance in the educational difficulties overcoming based on the supporting of the pupils" "subjectness position" in relation to their (educational) activity. As a result of their own practice reflection in the reflexive-activity approach there appeared the idea that the subjectness position manifested as the active and conscious attitude to the activity being carried out which is that internal resource that helps the child to develop in activity in many directions simultaneously (Y. V. Zaretskii, 2013). This notion allowed to reconsider the cases when in the course of the assistance providing in educational difficulties overcoming there were positive changes in the development and subjectum of the child, his self-reflection ability, different cognitive and personal qualities (V. K. Zaretskii \& Zaretskii, 2012). The data on the subjectness position in these researches were obtained by the method of participant observation and qualitative analysis of the pupils' learning tasks solving protocols.

The question arose before us: Is it possible to identify and examine the subjectness position with the help of psychological methods? The answer to it seemed to be especially important in the light of the need to develop the operational and convenient methods for diagnosing of the subjectness position as the important resource for the child development. In order to answer this question, we developed our own questionnaire "The Subjectness Position" in accordance with the theoretical concepts concerning this construct (Y. V. Zaretskii, Zaretskii, \& Kulagina, 2014), and also formed a battery of four additional techniques that allow to consider features of different age children and adolescents attitude to the educational activity from different foreshortenings:

- the questionnaire for the research of the older adolescents and youngster's educational motivation (Ch. S. Spielberger, adaptation by A. D. Andreeva) (completed by adolescents);

- the method "The Orientation to the Knowledge Acquisition" by E. P. Ilyin and N. A. Kurdyukova (completed by junior pupils instead of the Spilberger-Andreeva questionnaire);

- the questionnaire "The School Situation" developed by V. K. Zaretskii, A. B. Kholmogorova;

- the modified method for the instant diagnosis of pupils' educational preferences (Pakhomova, 2004).

- the modified method of unfinished sentences, the statements themselves are taken from the method of Nutten (2004). 


\section{The main results of the research}

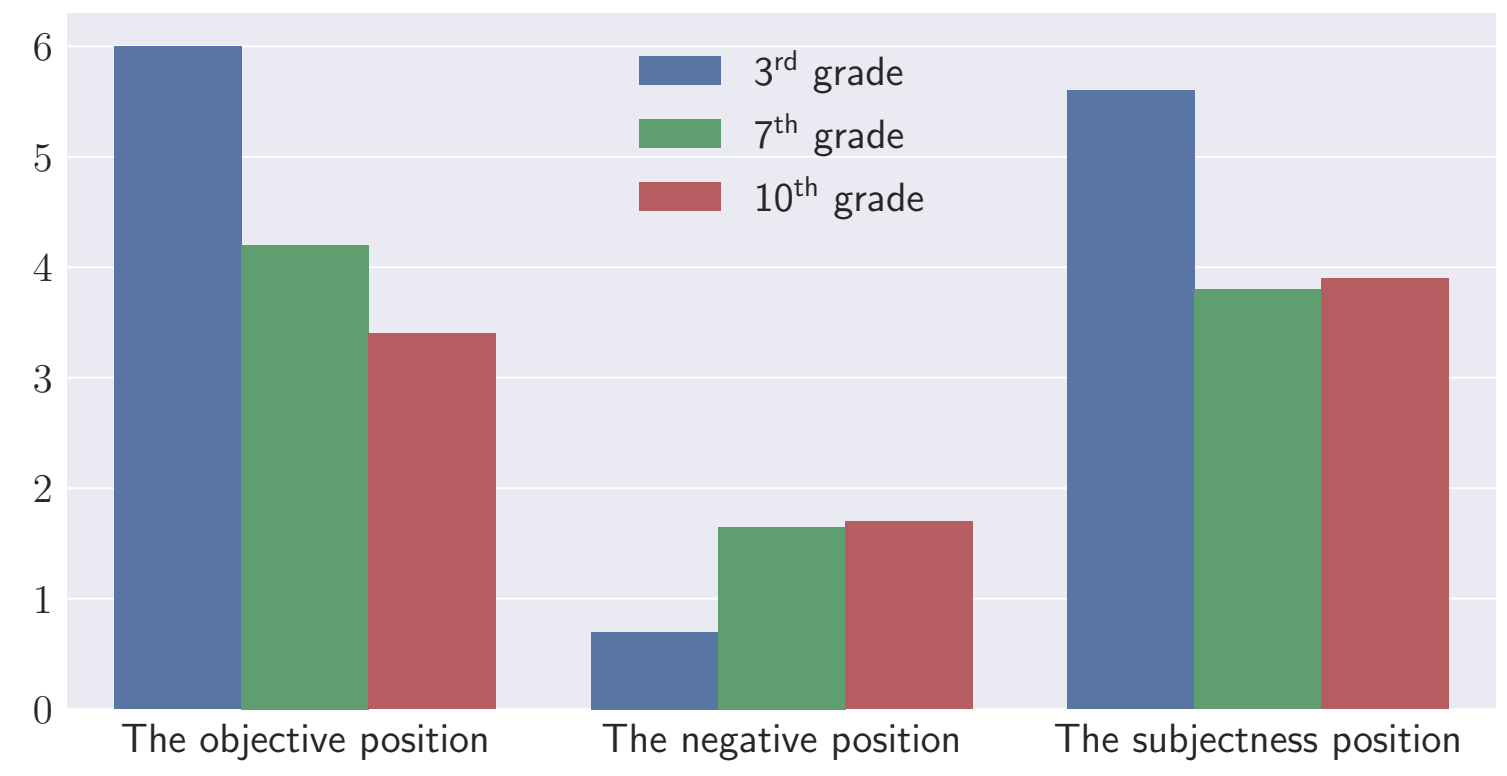

Figure 1. Attitude to the educational activity based on the results of the questionnaire "The subjectness position" of pupils of the $3^{\text {rd }}, 7^{\text {th }}$ and $10^{\text {th }}$ grades of general academic schools

From the figure above, it can be seen that the indicators of the subjectness and abjectness' positions are higher in the third grades, while the negative position is more pronounced in the seventh and tenth grades. When comparing the third and tenth grades, it is clear that those trends in the change of the objective position that were observed when comparing the third and seventh grades continue to increase, while the negative and subjectness positions remain practically at the same level.

Thus, it can be seen that the subjectness position is most pronounced in the third grade and its expressiveness decreases to the adolescence after which the decrease stops, but the increase in the tenth grade does not occur.

In order to check whether these changes are related to the age-related patterns, we conducted the research in the physical and mathematical gymnasium, where, on the one hand, the most motivated children are selected, on the other hand, in the process of educational activity the attention is paid to the development of the pupils' subjectness position.

As we see the tendency of changes in the pupils' subjectness position differs from the one we observed comparing the indicators of general academic school's pupils, it remains unchanged throughout the entire period of study. That is, the education built in a special way can encourage the keeping of the active and conscious position with which the child comes to school. 


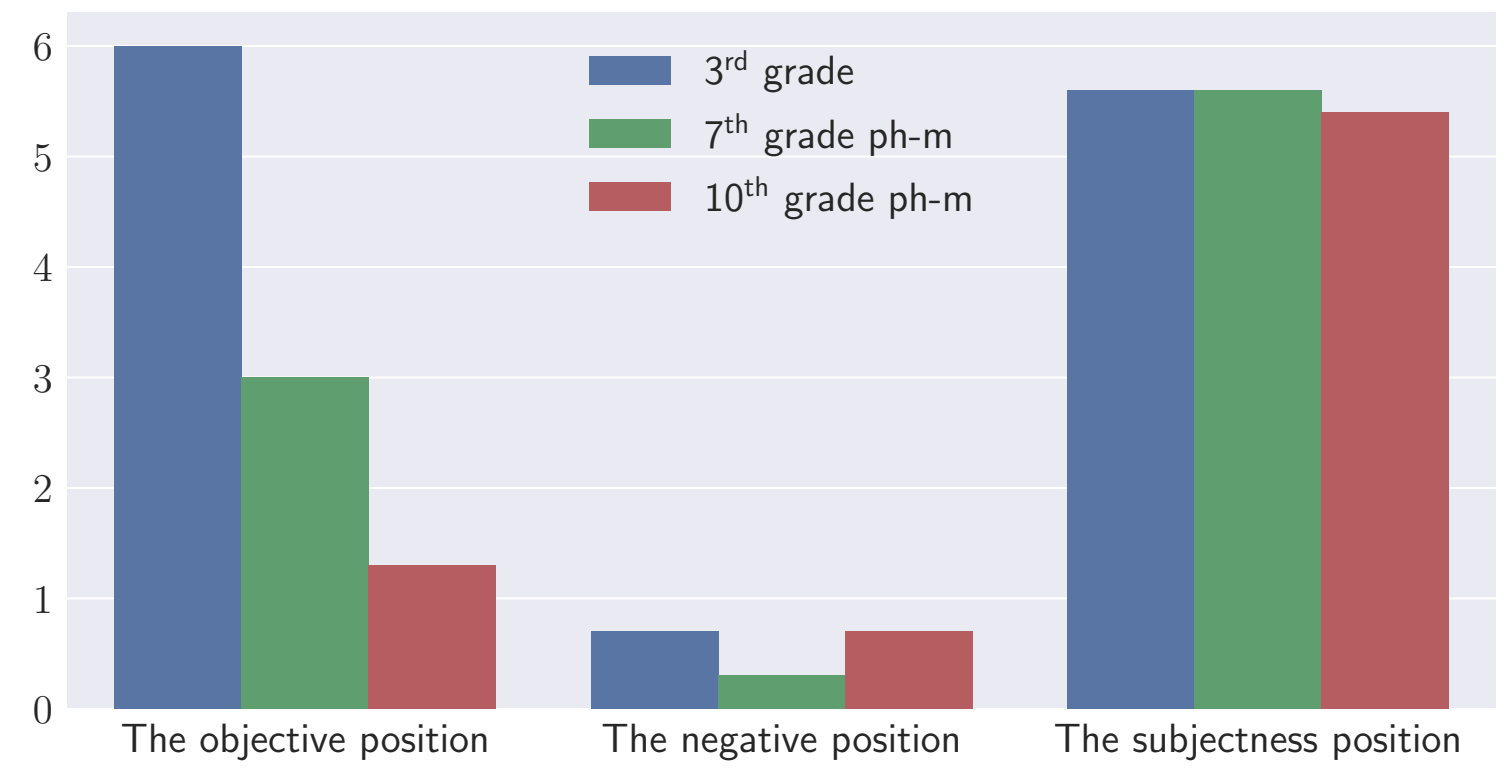

Figure 2. Attitude to the educational activity based on the results of the questionnaire "The subjectness position" of pupils of the 3rd grades of general academic schools, $7^{\text {th }}$ and $10^{\text {th }}$ grades of the physical and mathematical gymnasium

In the context of our understanding of the subjectness position the results obtained can indicate that while schooling the pupils' own activity in the educational activities decreases and awareness and involvement in the educational activities diminish (less and less attempts to blow up difficulties and perform the reflection of their own mistakes). On the other hand, the objective position also falls to adolescence and continues to decrease in pre-adult age, i.e., the willingness to obey the rules, to act according to the teacher's instructions; the teacher's praise no longer has that motivating importance as in the primary school. In addition, the negative attitude towards education is increasing. It seems that the decrease in the objective position could be considered as a positive change, but taking into account the lack of the subjectness position increase and the increase of the negative position, these changes result in indifference or negative attitudes toward educational activities in general. Such indifference when none of the positions is expressed we designated as the "passive position". Using other method, we tried to describe the differences between the indicated positions. For better appearance, let's consider the diagram.

In the vivid form, we see the differences between some of the groups we have examined. The subjectness position looks like some standard - pupils occupying this position have high motivation, they study with interest and meaningfully, they have good relations with teachers, there are no conflicts about studying at home and there is no absenteeism.

The group with the objective position noticeably comes short of the motivation, but in whole it considers the schooling interesting, although the pupils consider the subjects themselves senseless; the relations with the teachers are good, but there are conflicts at 


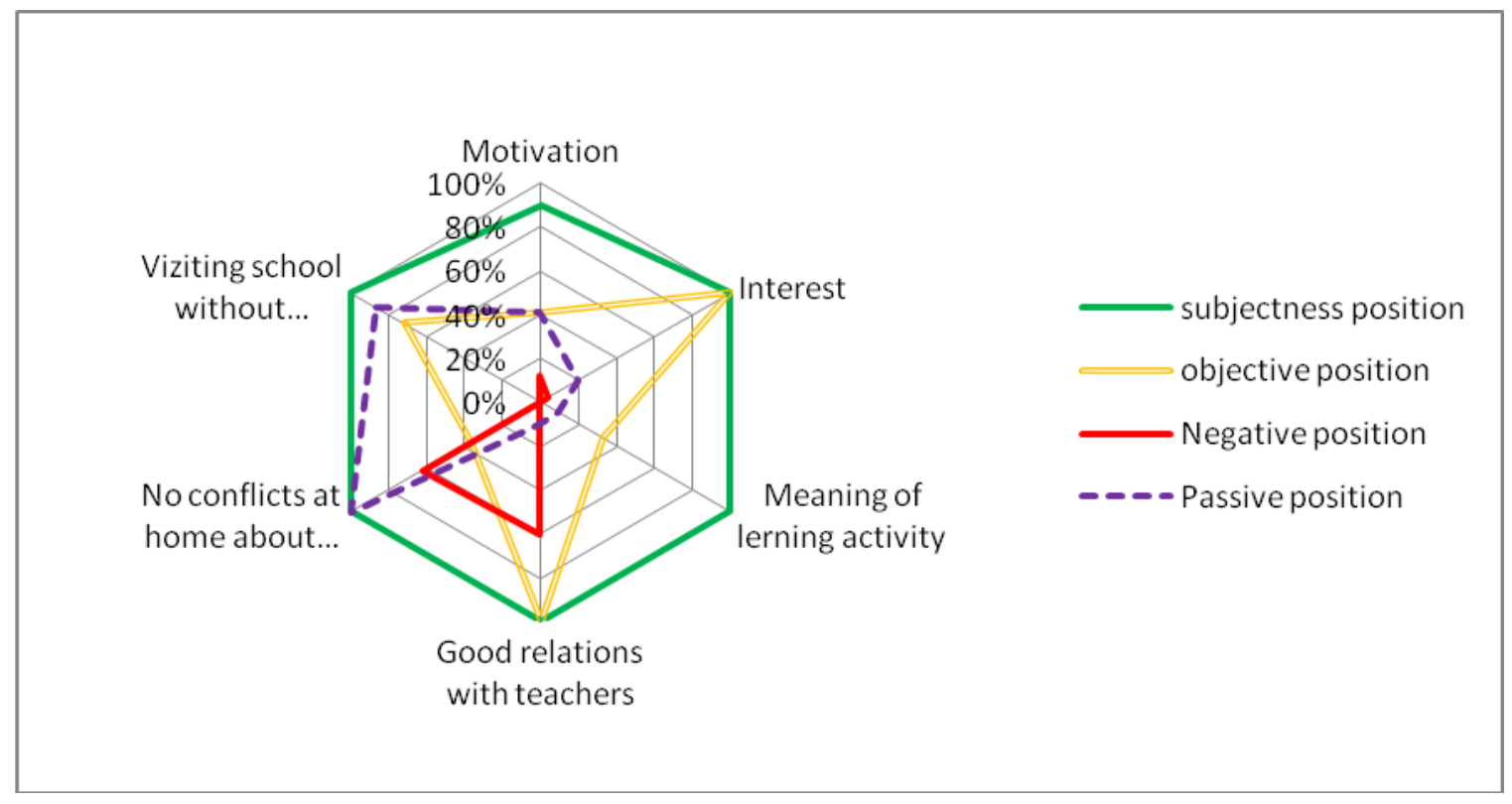

Figure 3. The comparison of the main indicators in groups with pronounced subjectness, objective, passive and negative positions (only pupils of general academic schools participated in the comparison).

home (many pupils in this group talk about pressure and parents' checks), there appears the absenteeism, but only of minority in this group pupils.

The pupils with the "passive" position also have an average motivation, but the meaningfulness and interest in education are absent; the relations with teachers are also in a poor state, there are no conflicts at home (we assume that just no one at home is interested in schooling). The absenteeism for this group is also not very characteristic.

Finally, the group with the expressed negative position has the worst indicators of educational motivation, for them the schooling completely has no meaning and interest, although there are good relations with some teachers, conflicts at home also occasionally occur $(50 \%)$, and this is exactly that group that regularly skips classes.

Thus, on the one hand, the subjectness position is connected with the extremely important aspects of educational activity, primarily: motivation, meaningfulness, relations with teachers and parents. At the same time, the research of the subjectness position evidence at different ages showed that the educational system existing in Russia does not support the subjectness position of the pupils. Simultaneously with the public educational paradigm there are pedagogical systems that successfully support the subjectness position of children and promote the development of the pupils' conscious and active attitude to the educational activities. And this apposes new tasks for us to study the influence of various pedagogical environments on the development of the subjectness position. 


\title{
The questionnaire "The Subjectness Position"
}

\author{
Surname, first name: \\ School: \\ Age: \\ Grade: \\ Date:
}

Instructions: Please, answer the questions expressing your consent ("Yes", "More likely yes, than no") or disagreement ("No", "More likely no, than yes"). Tick the appropriate box. Your answers will be known only to specialists conducting the survey and will not be reported to any classmates, parents, teachers, or any of the specialists working in the school.

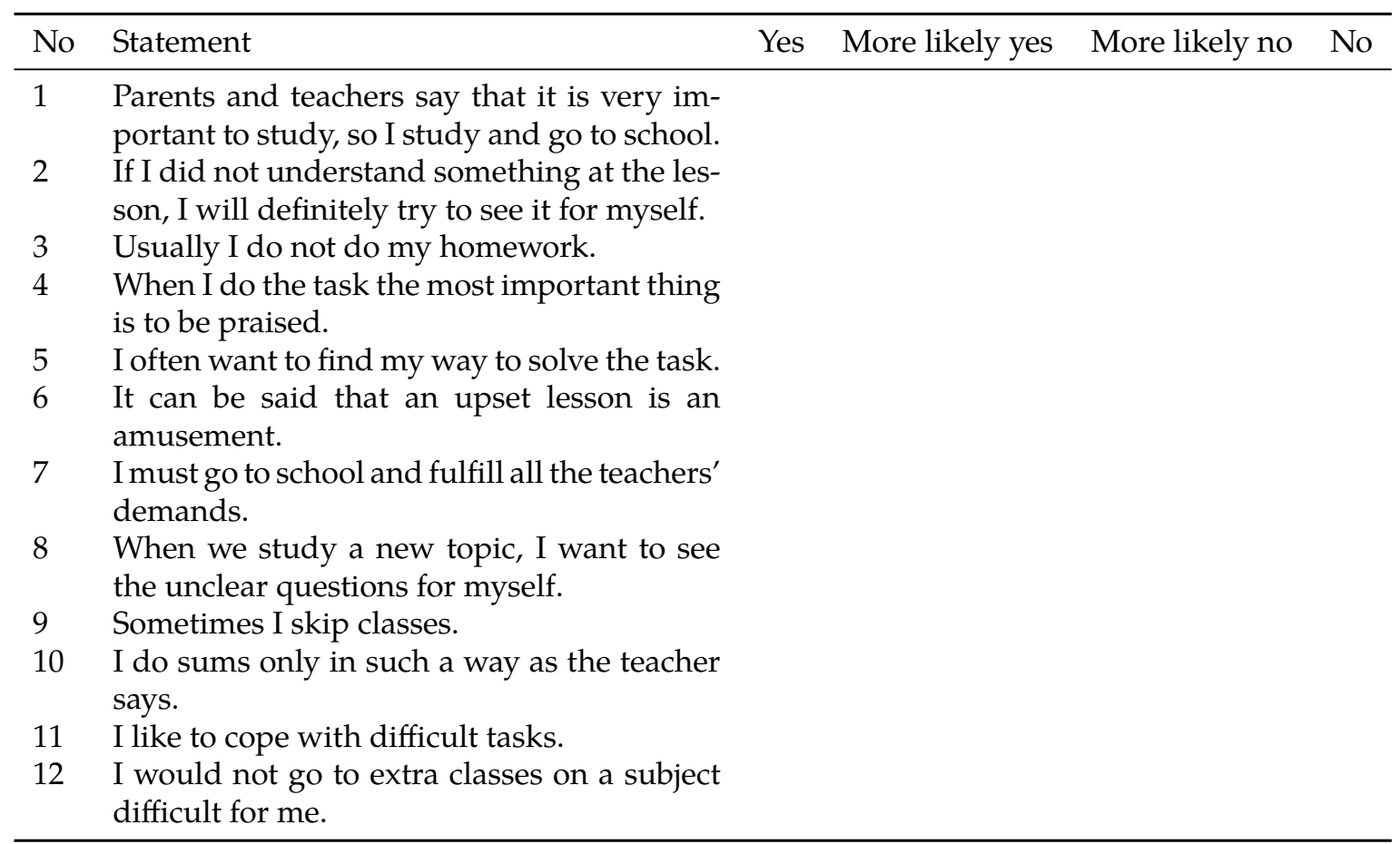

\section{The keys:}

- Answers "Yes" - 2 points, answers "More likely yes" - 1 point, "No" and "More likely no" -0 points.

- The objective position $-1,4,7,10$

- The subjectness position - 2, 5, 8, 11

- The negative position $-3,6,9,12$ 


\section{References}

Deci, E. L., \& Ryan, R. M. (2002). Handbook of self-determination research. Rochester: University of Rochester Press.

Engeström, Y. (2006). Development, movement and agency: Breaking away into my corrhizae activities. In K. Yamazumi (Ed.), Building activity theory in practice: Toward the next generation. Osaka: Center for Human Activity Theory.

Grawe, K. (2006). Agents of change in the processes of psychotherapy. IFP Newsletter, 1, 7-17.

Griffin, E. A. (1997). A first look at communication theory (3rd ed ed.). New York: McGrawHill.

Mangels, J. A., Butterfield, B., Lamb, J., Good, C., \& Dweck, C. S. (2006). Why do beliefs about intelligence influence learning success? A social cognitive neuroscience model. Social Cognitive and Affective Neuroscience, 1(2), 75-86. doi: 10.1093/scan/nsl013

Nutten, J. (2004). Motivation, action and the prospect of the future. Moscow: Smysl.

Obukhov, A. S. (2010). The age aspect of the research activity development: from spontaneous behavior to subjectum formation. In A. S. Obuhov (Ed.), Research activity of pupils: from the kindergarten to the university: the scientific and methodological collection in two volumes (pp. 42-48). Moscow: All-Russian Public Movement of Creative Pedagogues "Researcher"; MPSU.

Pakhomova, O. (2004). Difficulties of translation. http://psy . 1september . ru/article. php ?ID $=200403314$.

Rice, F., \& Dolgin, K. (2012). Psychology of adolescence and pre-adult age. St. Petersburg: Peter. Vygotsky, L. S. (1984). Collected works in 6 volumes. Vol. 4. Moscow: Pedagogika.

Yakimanskaya, I. S. (1996). Personally oriented education in the modern school. Moskow: September.

Zaretskii, V. K. (2001). What does the consultant on the problem solving process. In V. K. Zaretskii \& M. M. Gordon (Eds.), Summer school for children with developmental features: the work experience. (pp. 107-120). Nytva: REM, IPI RAE.

Zaretskii, V. K. (2013). The formation and essence of the reflexive-activity approach in the provision of the consultative psychological counseling. Consultative psychology and psychotherapy, 2, 8-37.

Zaretskii, V. K., \& Zaretskii, Y. V. (2012). Subjectness position of the child in the educational difficulties overcoming (the case from practice). Consultative psychology and psychotherapy(2), 110-133.

Zaretskii, Y. V. (2013). The subjectness position in relation to the educational activity as the resource for development and the subject of research. Consultative psychology and psychotherapy(2), 110-128.

Zaretskii, Y. V., Zaretskii, V. K., \& Kulagina, I. Y. (2014). Metodika issledovaniya sub"ektnoi pozitsii uchashchikhsya raznykh vozrastov [Methods of study of a subject position of pupils]. Psikhologicheskaya nauka i obrazovanie [Psychological science and Education](1), 98-109.

Zukerman, G. A., \& Wenger, A. L. (2010). Development of educational independence. Moscow: EHDE. 